\title{
Neighborhood Socioeconomic Status and All-Cause Mortality
}

\author{
Hans Bosma, H. Dike van de Mheen, Gerard J. J. M. Borsboom, and Johan P. Mackenbach
}

This study sought to determine the contribution of neighborhood socioeconomic status to all-cause mortality and to explore its correlates. As part of the longitudinal "Gezondheid en LevensOmstandigheden Bevolking en omstreken" (GLOBE) study in the Netherlands, 8,506 randomly selected men and women aged 15-74 years from 86 neighborhoods in the city of Eindhoven reported on their socioeconomic status in the 1991 baseline survey. During the 6-year follow-up, 487 persons died. Neighborhood socioeconomic status was derived from individual reports on socioeconomic status. Its effect on mortality was stringently controlled for four individuallevel socioeconomic indicators. Persons living in a neighborhood with a high percentage of unemployed/disabled or poor persons had a higher mortality risk than did those living in a neighborhood with a low percentage of unemployed/disabled or poor persons. This was independent of individual socioeconomic characteristics, including individual unemployment/disability or reports of severe financial problems. Educational and occupational neighborhood indicators were similarly, but less strongly, related to mortality. The prevalence of poor housing conditions, social disintegration, and unhealthy psychologic profiles and behaviors was higher in neighborhoods with a low socioeconomic status. Contextual effects of socioeconomic status may thus be due to one or more of these specific circumstances. The findings indicate potential public health benefits of modifying socioeconomic characteristics of areas. Am J Epidemiol 2001;153:363-71.

mortality; social class; social environment; unemployment

Recently, there has been much interest in the adverse health consequences of living in districts, regions, wards, or neighborhoods characterized by poor socioeconomic conditions (1-21). Although some studies reported negative findings (22-25), there is increasing support for the hypothesis that living in such areas has negative effects on physical and mental health for both people with a high socioeconomic status and those with a low socioeconomic status (26-32). This may have important consequences for public health initiatives since effects of area socioeconomic status-net of individual socioeconomic status-suggest that health policies should focus not only on individuals, but also on the socioeconomic environment in which people live (26-32). However, only a few studies stringently adjusted for equivalent measures of socioeconomic status on the individual level. Hence, there is still the possibility that the adverse effect of living in an area with a low socioeconomic status only holds for the low-class inhabitants and not for their better-off neighbors in the same area.

Received for publication February 3, 1999, and accepted for publication March 6, 2000.

Abbreviation: GLOBE study, Gezondheid en LevensOmstandigheden Bevolking Eindhoven en omstreken (Dutch acronym for health and living conditions of the population of Eindhoven and its surroundings).

From the Erasmus University Rotterdam, Department of Public Health, 3000 DR Rotterdam, the Netherlands.

Correspondence to Prof. Dr. Johan P. Mackenbach, Erasmus University Rotterdam, Department of Public Health, P. O. Box 1738, 3000 DR Rotterdam, the Netherlands.
Dutch longitudinal data (Gezondheid en Levens Omstandigheden Bevolking Eindhoven en omstreken (Dutch acronym for health and living conditions of the population of Eindhoven and its surroundings) (GLOBE) study (33)) on 8,506 men and women living in 86 neighborhoods in the city of Eindhoven (191,000 inhabitants in 1991) were used to determine whether living in a neighborhood with a low socioeconomic status is related to 6-year all-cause mortality. In the analyses, we stringently controlled for individual socioeconomic status by adjusting each neighborhood socioeconomic indicator, aggregated from individual reports (e.g., percent of blue-collar workers in neighborhood), for four individual socioeconomic indicators, including the equivalent individual report (e.g., being a blue-collar worker or not). To obtain more information on the mechanisms underlying the association between neighborhood socioeconomic status and mortality $(4,28)$, we further examined whether people living in varying socioeconomic neighborhoods differed in more specific housing, social, psychologic, and behavioral characteristics.

\section{MATERIALS AND METHODS}

\section{Study population}

Data were collected within the framework of the GLOBE study (33). A postal survey was conducted in 1991 among 27,070 noninstitutionalized inhabitants (aged 15-74 years) of Eindhoven and a number of surrounding municipalities, all in the southeastern part of the Netherlands. Stratified by 
age and zip code, the sample was randomly drawn from the municipal population registries. The response rate was 70.1 percent, which resulted in a study population of 18,973 respondents. The response rates were not substantially different by age, sex, marital status, level of urbanization, or social class (as indicated by zip code) (33).

In Eindhoven, the major city in the study, 8,506 GLOBE participants who reported on their current or last occupation (younger people, mainly students, were thus excluded) could be attributed to 86 administrative neighborhoods (areas) with relatively homogeneous housing. On average, there were 99 respondents in a neighborhood (range, 5-386). Eindhoven has a total of 106 areas, but some have only few or no inhabitants. In 1991, the 86 neighborhoods contained 191,000 inhabitants (all ages), with an average of 2,221 inhabitants per neighborhood.

Municipal population registers provided information on all-cause mortality during the follow-up period until mid1997. These have a virtually complete coverage of the population (34). During the 6-year follow-up period, 487 men and women died (6 percent).

\section{Individual and neighborhood socioeconomic status}

Similar measures were used to indicate socioeconomic status on the individual and neighborhood levels. To indicate the socioeconomic status of the neighborhood, we aggregated individual reports on socioeconomic status to the neighborhood level. An advantage of this approach is that the effect of neighborhood socioeconomic status on mortality can be stringently controlled for equivalent measures on the individual level. This allows an accurate examination of genuine contextual effects and, to a large extent, excludes the possibility that any adverse effect of poor neighborhoods is fully based on poorer people living in poorer neighborhoods.

Four indicators of individual socioeconomic status were used: last attained educational level of respondent, current or last occupational level of household breadwinner (35), being disabled or unemployed, and presence of severe financial problems in the household. Being or not being disabled or unemployed was based on a question asking for the subjects' main activity for which they received income or special social security benefits. Disability implied long-term disability. Severe financial problems were self-reported by a single item about whether or not the household had many problems with making ends meet.

Neighborhood socioeconomic status was indexed by four equivalent indicators based upon aggregated individual GLOBE data: the percent of subjects reporting primary schooling only (range, $0-44$ percent), the percent of subjects reporting that they were unskilled manual workers (range, 0-39), the percent of subjects reporting that they were unemployed or disabled (range, 0-28), and the percent of subjects reporting severe financial problems (range, 0-15). Both continuous percentage scores and quartiles of neighborhoods based on the percentage in the aggregated data were used; each quartile contained about 22 neighborhoods (86 neighborhoods total).
Disability and unemployment were combined because both groups share the characteristic of being without paid work and receiving social security benefits. Moreover, they were combined because it is likely that many disabled persons would have been assigned to the unemployed group in countries other than the Netherlands. In the Netherlands, the relatively generous disability benefit scheme has been used on a large scale by employers to give the unemployed a reasonable level of income compensation. Our findings will not be confounded by prevalent disease (as the main cause of disability) because the effect of the neighborhood percent reported as unemployed or disabled will be controlled for individual disability or unemployment and indicators of prevalent disease.

\section{Correlates of neighborhood socioeconomic status}

Twelve individual characteristics were explored for their association with neighborhood socioeconomic status. These could be classified into four groups: housing conditions, and social, psychologic, and behavioral factors. The three housing conditions were based on self-reported cold or draft in the house (yes, no), condensation (yes, no), or moisture and damp in the house (yes, no). The three social characteristics were based on self-reported perception of vandalism in neighborhood (yes, no), social difficulties with family members and neighbors (subjects in the most adverse quintile of the sum of eight five-point items asking for difficulties in contacts with eight separate groups of important others, including neighbors vs. the others), and noise pollution from neighbors (yes, no). The three psychologic factors were based on self-reported low control (subjects in the most adverse quintile of the sum of 11 five-point items asking for an external locus of control vs. the others), passive coping (subjects in the most adverse quintile of the sum of eight five-point items asking for an inactive style of coping vs. the others), and depressive coping (subjects in the most adverse quintile of the sum of seven five-point items asking for a depressive reaction pattern when faced with problems vs. the others). The three behavioral factors were based on selfreported current smoking (yes, no), physically inactivity in leisure time (subjects reporting no time spent on sports, gardening, walking, or cycling during leisure time vs. the others), and excessive alcohol consumption (subjects drinking more than six alcoholic beverages on 3 or more days a week or more than four beverages on 5 or more days a week vs. the others). More information on the measurement of these characteristics can be found elsewhere $(36,37)$.

\section{Data analysis}

Each separate neighborhood socioeconomic indicator was related to all-cause mortality. The effect of individual socioeconomic status was also determined. The effect of neighborhood socioeconomic status (e.g., percent of subjects reporting to be unskilled manual workers) was estimated as both unadjusted and adjusted for its individuallevel equivalent socioeconomic measure (e.g., occupational level). Any residual confounding by socioeconomic status 
on the individual level was taken into account by controlling for all four individual-level indicators of socioeconomic status. Age, sex, and baseline health status were controlled for in these analyses. Neighborhood socioeconomic status had similar effects on mortality in men and women and in the young and old (there were no statistically significant interactions with sex and age). Therefore, no sex- or age-specific analyses were performed. Baseline health status was indicated by two dummy variables indicating whether or not the respondent reported any less (e.g., hypertension, migraine) or more (e.g., heart disease, cancer) severe chronic conditions in a 23 -item checklist.

We further explored the associations between neighborhood socioeconomic status and the adverse housing, social, psychologic, and behavioral conditions. Neighborhood socioeconomic status was therefore related to individual reports of any of these conditions, adjusting for all four individual-level indicators of socioeconomic status, age, sex, and baseline health status. Since the information on these conditions was available for only a subsample that was extensively interviewed ( $n=2,726)$ (33), detailed multivariate analyses determining the contribution of reported adverse conditions to the neighborhood-mortality association were precluded.

Because individuals (level one) were nested within neighborhoods (level two), the analyses with death or individual reports of problems as the outcome were done with multilevel logistic regression using the MLN program $(38,39)$. The probability of dying of the $i$ th individual in the $j$ th neighborhood was modeled as follows:

$$
\log \left(\pi_{i j} /\left(1-\pi_{i j}\right)\right)=\alpha+\beta_{1} x_{1 i j}+\ldots+\beta_{p} x_{p i j}+\gamma_{1} z_{1 j}+u_{j}
$$

where $\alpha$ is the constant; $\beta_{1}$ to $\beta_{p}$ are the regression coefficients of the individual-level variables $x_{1}$ to $x_{p} ; \gamma_{1}$ is the regression coefficient of neighborhood socioeconomic status $z_{1}$, and $\mu_{j}$ is the neighborhood level residual (random variable).

\section{RESULTS}

Table 1 shows that both low individual socioeconomic status and low neighborhood socioeconomic status were related to mortality. For example, subjects with only primary schooling had a 1.65 higher risk of dying during follow-up compared with their highly educated counterparts. A similar odds ratio was obtained for subjects living in a neighborhood in which a high percentage of residents had only primary schooling compared with those living in a neighborhood with a low percentage having only primary schooling (odds ratio $=1.73$ ). Subjects who were self-employed and those with severe financial problems had particularly elevated odds of dying (odds ratio $=2.37$ and 2.16, respectively) as did subjects living in neighborhoods in which a high percentage were unemployed or disabled or were reporting severe financial problems (odds ratio $=1.78$ and 1.47, respectively).

The multilevel analysis showed significant variability in mortality risks among neighborhoods $\left(\chi^{2}=4.3(1 \mathrm{df}), p=\right.$
0.04). When the neighborhood socioeconomic status and confounders were taken into account, no between-neighborhood variation was left. There were no statistically significant cross-level interactions between individual and neighborhood socioeconomic statuses. This indicates that low neighborhood socioeconomic status was related to increased risks of mortality in both subjects with a high and those with a low socioeconomic status. Finally, findings were similar across neighborhoods differing in the number of respondents, i.e., the results are probably not biased by the fact that the socioeconomic status of some neighborhoods was derived from data obtained from few respondents only.

The independence of neighborhood socioeconomic status and individual socioeconomic status is shown in figure 1 for the educational indicators. Living in a poorly educated neighborhood increased probabilities of dying for both highly and poorly educated individuals. Similarly, a low individual educational level increased probabilities of dying within both highly and poorly educated neighborhoods. For example, 3.6 percent of the subjects with a low educational level living in a neighborhood with many respondents with only primary schooling were estimated to die within the follow-up period compared with 2.4 percent of their poorly educated counterparts living in highly educated neighborhoods. The 1.7 percent deaths in highly educated subjects living in highly educated neighborhoods compared with the 3.6 percent deaths in poorly educated subjects living in poorly educated neighborhoods indicates the cumulative effects of individual and neighborhood socioeconomic statuses.

The neighborhood effects adjusted for the individuallevel equivalent measure of socioeconomic status is shown in table 2, model 1. Except for the neighborhood occupational level (the percent of unskilled workers), effects were statistically significant for subjects in the socioeconomically most adverse areas. For example, the risk of mortality for subjects living in neighborhoods with a high percentage of subjects who reported only primary schooling was 1.50 times higher than the risk for their counterparts in highly educated neighborhoods. The decrease in odds ratios compared with the unadjusted model in table 1 is the result of subjects in neighborhoods with a low socioeconomic status having a higher risk of having a low socioeconomic status themselves.

When we adjusted for all four individual socioeconomic indicators in model 2, the odds ratios of neighborhood socioeconomic status decreased further, causing only one odds ratio (for the percent reporting as unemployed or disabled) to remain statistically significant. The other odds ratios were generally in the expected direction, however. Moreover, using the continuous percentage score for neighborhood socioeconomic status revealed that the presence of severe financial problems in a neighborhood was also statistically significantly related to mortality. The odds ratios were 1.32 and 1.60 for a 10 percent increase in the neighborhood percent of subjects reporting that they were unemployed or disabled and those reporting severe financial problems, respectively. These effects were independent of individual educational and occupational levels, whether or 
TABLE 1. Number of respondents and odds ratios of mortality and 95 percent confidence intervals by individual and neighborhood socioeconomic status, adjusted for age, sex, and baseline health status ( $n=8,506 ; 487$ deaths), longitudinal GLOBE study, Eindhoven, the Netherlands, 1991-1997

\begin{tabular}{|c|c|c|c|}
\hline & No. & $\begin{array}{l}\text { Odds } \\
\text { ratio }\end{array}$ & $\begin{array}{c}95 \% \\
\text { confidence } \\
\text { interval }\end{array}$ \\
\hline \multicolumn{4}{|l|}{ Individual educational level** } \\
\hline 1 High & 1,596 & 1.00 & \\
\hline 2 & 1,787 & 1.20 & $0.83,1.72$ \\
\hline 3 & 3,326 & 1.30 & $0.94,1.79$ \\
\hline 4 Low & 1,797 & 1.65 & $1.19,2.28$ \\
\hline \multicolumn{4}{|l|}{ Neighborhood educational level } \\
\hline 1 Living in best-off quartile & 1,026 & 1.00 & \\
\hline 2 & 2,947 & 1.37 & $0.93,2.02$ \\
\hline 3 & 2,204 & 1.31 & $0.89,1.93$ \\
\hline 4 Living in worst-off quartile & 2,329 & 1.73 & $1.18,2.54$ \\
\hline \% score (range: $0-44) \dagger$ & & 1.15 & $1.04,1.27$ \\
\hline \multicolumn{4}{|l|}{ Individual occupational levelł } \\
\hline 1 High & 988 & 1.00 & \\
\hline 2 & 3,581 & 1.53 & $1.07,2.17$ \\
\hline 3 Self-employed & 360 & 2.37 & $1.43,3.94$ \\
\hline 4 & 2,037 & 1.82 & $1.27,2.61$ \\
\hline 5 Low & 1,540 & 1.82 & $1.24,2.68$ \\
\hline \multicolumn{4}{|l|}{ Neighborhood occupational level } \\
\hline 1 Living in best-off quartile & 962 & 1.00 & \\
\hline 2 & 2,179 & 1.06 & $0.72,1.56$ \\
\hline 3 & 2,791 & 1.48 & $1.04,2.11$ \\
\hline 4 Living in worst-off quartile & 2,574 & 1.46 & $1.03,2.09$ \\
\hline$\%$ score (range: 0-39)† & & 1.14 & $1.02,1.27$ \\
\hline \multicolumn{4}{|c|}{ Individual unemployment or disability } \\
\hline 1 No & 7,465 & 1.00 & \\
\hline 2 Yes & 1,041 & 1.87 & $1.44,2.44$ \\
\hline \multicolumn{4}{|c|}{ Neighborhood unemployment or disability } \\
\hline 1 Living in best-off quartile & 1,610 & 1.00 & \\
\hline 2 & 1,986 & 1.38 & $0.97,1.97$ \\
\hline 3 & 2,876 & 1.46 & $1.04,2.04$ \\
\hline 4 Living in worst-off quartile & 2,034 & 1.78 & $1.26,2.52$ \\
\hline$\%$ score (range, $0-28) \dagger$ & & 1.53 & $1.23,1.90$ \\
\hline \multicolumn{4}{|c|}{ Individual severe financial problems } \\
\hline 1 No & 8,178 & 1.00 & \\
\hline 2 Yes & 328 & 2.16 & $1.42,3.28$ \\
\hline \multicolumn{4}{|c|}{ Neighborhood severe financial problems } \\
\hline 1 Living in best-off quartile & 1,466 & 1.00 & \\
\hline 2 & 2,314 & 1.05 & $0.76,1.44$ \\
\hline 3 & 2,993 & 1.26 & $0.94,1.68$ \\
\hline 4 Living in worst-off quartile & 1,733 & 1.47 & $1.07,2.02$ \\
\hline$\%$ score (range, $0-15) \dagger$ & & 2.03 & $1.40,2.93$ \\
\hline
\end{tabular}

* 1: university and higher vocational education; 2 : intermediate/higher general and intermediate vocational education; 3: lower general and lower vocational education; and 4: primary education only.

† Odds ratios for the percent scores indicate increase in odds when there is a 10-point increase in the percent score.

¥ 1: higher-grade professionals; 2: lower grade professionals or routine nonmanual workers; 3 : self-employed workers; 4: skilled manual workers; and 5: unskilled manual workers.

not subjects were disabled or unemployed themselves and whether or not subjects reported severe financial problems themselves.
The odds ratios in table 3 show that neighborhood socioeconomic status (percent reporting that they were unemployed or disabled, in quartiles) was related in the 


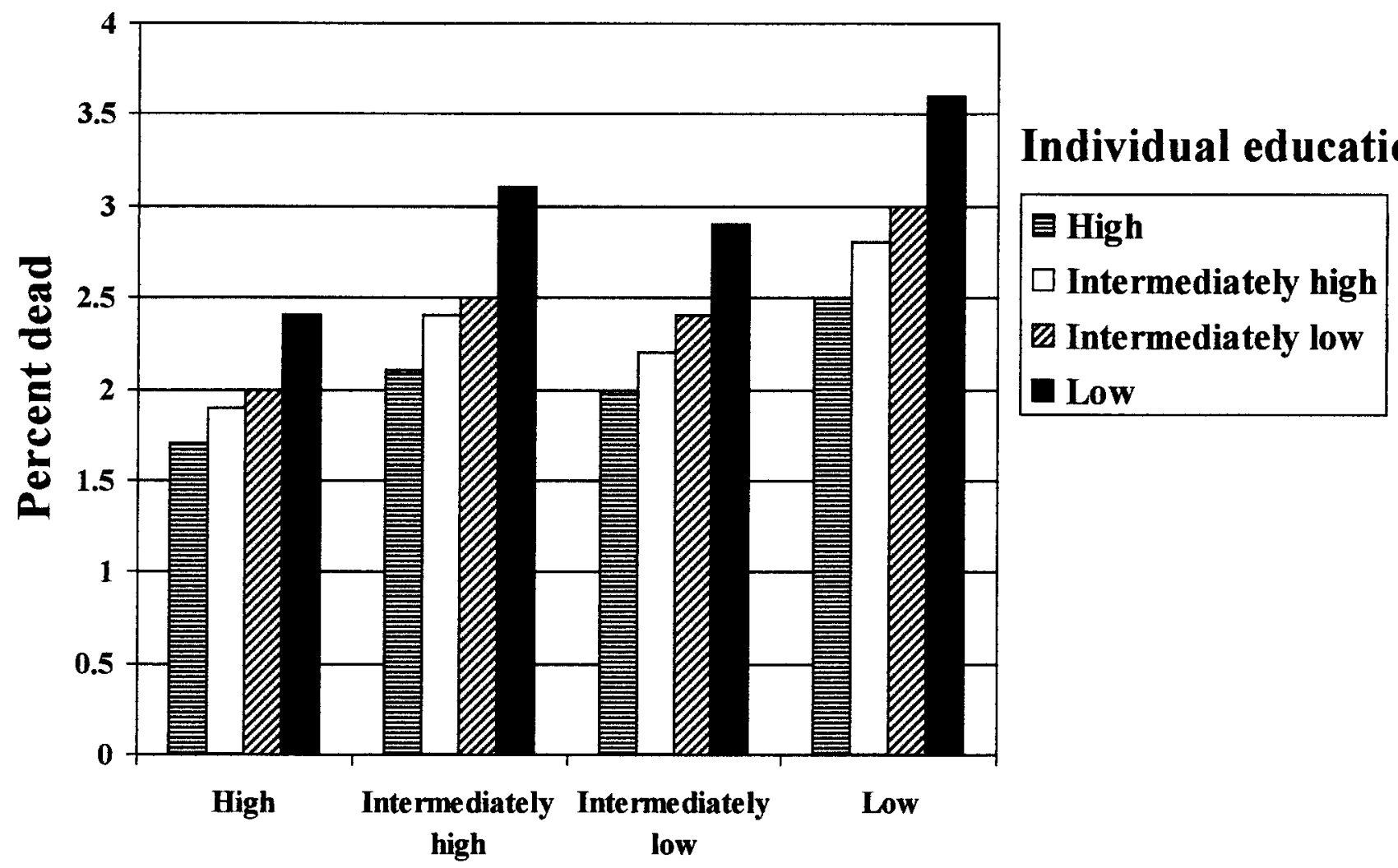

Neighborhood education

FIGURE 1. Percent deceased during follow-up by individual and neighborhood educational level. Estimated for men aged 49 years without baseline diseases ( $n=6,506$ deaths), longitudinal Globe study, Eindhoven, the Netherlands, 1991-1997.

predicted direction to all housing, social, psychologic, and behavioral factors. For example, individuals living in neighborhoods with a high percent of subjects reporting that they were unemployed or disabled more often reported that they experienced cold or draft in their houses (odds ratio $=2.29$ ), that they experienced vandalism in the neighborhood (odds ratio $=2.05$ ), that they used more passive instead of active coping (odds ratio $=1.46$ ), and that they more often did not engage in physical activity (odds ratio $=1.48$ ). The associations were independent of whether or not the subjects themselves had a high educational or occupational level, whether or not they were unemployed or disabled, and whether or not they had severe financial problems. There was no clear association between neighborhood socioeconomic status and excessive alcohol consumption. Similar associations were found with the other indicators of neighborhood socioeconomic status.

\section{DISCUSSION}

Our findings indicate that particular indicators of neighborhood socioeconomic status are related to longevity in
Dutch men and women in an urban setting. After the stringent control for individual socioeconomic status, the neighborhood percentage of unemployed or disabled persons and the percentage who reported severe financial problems continued to affect mortality risks. The educational and occupational indicators of neighborhood socioeconomic status were also related to mortality, but less strongly, and their effects were no longer statistically significant after the stringent individual-level control. The effects of neighborhood socioeconomic status are likely to be genuine contextual effects because we used similar measures on the individual level (individual reports) and the neighborhood level (aggregated individual reports). The association between neighborhood socioeconomic status and mortality was not only controlled for the individuallevel socioeconomic equivalent, but also for three other indicators of individual socioeconomic status. The higher mortality risk for subjects living in neighborhoods with many people who were unemployed or disabled or who reported severe financial problems thus not only holds for subjects who are unemployed, disabled, or poor themselves, but also for their employed, not disabled, and rich neighbors living in the same area. 
TABLE 2. Odds ratios and $95 \%$ confidence intervals for mortality by neighborhood socioeconomic status, adjusted for equivalent individual-level socioeconomic indicators, age, sex, and baseline health status (model 1) and additionally adjusted for all four individual-level socioeconomic indicators (model 2), longitudinal GLOBE study, Eindhoven, the Netherlands, 1991-1997*

\begin{tabular}{|c|c|c|c|c|}
\hline \multirow[b]{2}{*}{$\begin{array}{l}\text { Neighborhood } \\
\text { level }\end{array}$} & \multicolumn{2}{|c|}{ Model 1} & \multicolumn{2}{|c|}{ Model 2} \\
\hline & $\begin{array}{l}\text { Odds } \\
\text { ratio }\end{array}$ & $\begin{array}{c}95 \% \\
\text { confidence } \\
\text { interval }\end{array}$ & $\begin{array}{l}\text { Odds } \\
\text { ratio }\end{array}$ & $\begin{array}{c}95 \% \\
\text { confidence } \\
\text { interval }\end{array}$ \\
\hline \multicolumn{5}{|l|}{ Educational level } \\
\hline 1 Best-off quartile & 1.00 & & 1.00 & \\
\hline 2 & 1.27 & $0.86,1.88$ & 1.23 & $0.82,1.83$ \\
\hline 3 & 1.18 & $0.79,1.76$ & 1.13 & $0.76,1.70$ \\
\hline 4 Worst-off quartile & 1.50 & $1.00,2.24$ & 1.40 & $0.92,2.11$ \\
\hline$\%$ score (range, $0-44) \dagger$ & 1.10 & $0.99,1.22$ & 1.07 & $0.96,1.20$ \\
\hline \multicolumn{5}{|l|}{ Occupational level } \\
\hline 1 Best-off quartile & 1.00 & & 1.00 & \\
\hline 2 & 0.98 & $0.66,1.45$ & 0.96 & $0.65,1.43$ \\
\hline 3 & 1.31 & $0.91,1.89$ & 1.27 & $0.88,1.83$ \\
\hline 4 Worst-off quartile & 1.26 & $0.87,1.84$ & 1.19 & $0.81,1.73$ \\
\hline$\%$ score (range, $0-39$ )* & 1.08 & $0.96,1.22$ & 1.05 & $0.93,1.18$ \\
\hline \multicolumn{5}{|l|}{ Unemployed or disabled } \\
\hline 1 Best-off quartile & 1.00 & & 1.00 & \\
\hline 2 & 1.34 & $0.94,1.91$ & 1.27 & $0.89,1.83$ \\
\hline 3 & 1.40 & $1.00,1.95$ & 1.30 & $0.92,1.83$ \\
\hline 4 Worst-off quartile & 1.63 & $1.15,2.31$ & 1.47 & $1.02,2.11$ \\
\hline$\%$ score (range, $0-28$ )* & 1.42 & $1.14,1.77$ & 1.32 & $1.05,1.66$ \\
\hline \multicolumn{5}{|l|}{ Severe financial problems } \\
\hline 1 Best-off quartile & 1.00 & & 1.00 & \\
\hline 2 & 1.04 & $0.76,1.42$ & 0.98 & $0.71,1.34$ \\
\hline 3 & 1.24 & $0.92,1.65$ & 1.12 & $0.84,1.51$ \\
\hline 4 Worst-off quartile & 1.41 & $1.02,1.93$ & 1.22 & $0.88,1.69$ \\
\hline$\%$ score (range, $0-15) *$ & 1.90 & $1.31,2.75$ & 1.60 & $1.08,2.35 \ddagger$ \\
\hline \multicolumn{5}{|c|}{$\begin{array}{l}* n=8,506 \text {, with } 487 \text { deaths. } \\
\text { † Odds ratios for the percent scores indicate an increase in odds when there is a 10-point increase in the per- } \\
\text { nt score. } \\
\text { † The group of subjects }(n=96) \text { living in neighborhoods with the maximal percent of subjects reporting severe } \\
\text { ancial problems ( } 15.3 \text { percent) causes the continuous percent score to have a significant and strong associa- } \\
n \text { with mortality. Because the quartile categorization may be too crude, it did not indicate an equally strong asso- } \\
\text { tion. Quadratic and cubic terms indicative of nonlinear associations were not significant. }\end{array}$} \\
\hline
\end{tabular}

\section{Adverse conditions in neighborhoods with a low socioeconomic status}

Subjects living in the neighborhoods with a low socioeconomic status reported adverse conditions more often than did their counterparts in better-off neighborhoods. This again holds both for subjects with a high and those with a low socioeconomic status. The varying adverse conditions may be causally related and may be contributing to the pathway between socioeconomic context and individual risk of mortality. The poor physical environment (poor quality housing, e.g., cold, drafty, or damp houses) in neighborhoods with a low socioeconomic status may adversely affect the social environment by increasing social disintegration and decreasing social cohesion and public commitment (e.g., vandalism and noise pollution neighbors) $(40,41)$. Our finding that particularly the percentage of subjects in a neighborhood who reported that they were unemployed or disabled was independently related to mortality may also be interpreted as a con- textual effect of social exclusion, i.e., poor social cohesion between the unemployed and employed (42). The disintegration of the social fabric may further generate an environment of hopelessness and powerlessness that may become manifest in unhealthy individual psychologic profiles (e.g., low control, passive coping). Such profiles are likely to negatively affect the ability to quit unhealthy lifestyles (e.g., smoking and no physical activity). These varying gloomy characteristics may well contribute to a higher general susceptibility in areas with a low socioeconomic status. This may underlie the association with all-cause mortality in our study and a range of causes of death in another study (18). The hypothesized causal pathways between neighborhood socioeconomic status and mortality remain to be tested in further studies, however.

\section{Are neighborhood effects overestimated?}

Some methodological aspects may have caused overestimated effects of neighborhood socioeconomic status. First, 
TABLE 3. Odds ratios and 95 percent confidence intervals of adverse housing and social, psychologic, and behavioral factors by the neighborhood percent of subjects reporting that they were unemployed or disabled (in quartiles), adjusted for age, sex , baseline health status, and all four individual-level socioeconomic indicators, longitudinal GLOBE study, Eindhoven, the Netherlands, 1991-1997

\begin{tabular}{|c|c|c|c|c|c|c|c|}
\hline & \multicolumn{7}{|c|}{ Unemployed or disabled (quartiles) } \\
\hline & \multirow[b]{2}{*}{$\begin{array}{c}1 \text { (best) } \\
\text { (reference) }\end{array}$} & \multicolumn{2}{|c|}{2} & \multicolumn{2}{|c|}{3} & \multicolumn{2}{|c|}{4 (worst) } \\
\hline & & $\begin{array}{l}\text { Odds } \\
\text { ratio }\end{array}$ & $\begin{array}{c}95 \% \\
\text { confidence } \\
\text { interval }\end{array}$ & $\begin{array}{l}\text { Odds } \\
\text { ratio }\end{array}$ & $\begin{array}{c}95 \% \\
\text { confidence } \\
\text { interval }\end{array}$ & $\begin{array}{l}\text { Odds } \\
\text { ratio }\end{array}$ & $\begin{array}{c}95 \% \\
\text { confidence } \\
\text { interval }\end{array}$ \\
\hline \multicolumn{8}{|l|}{ Housing factors } \\
\hline Cold/draft & 1.0 & 1.49 & $1.05,2.12$ & 2.05 & $1.47,2.87$ & 2.29 & $1.64,3.20$ \\
\hline Condensation & 1.0 & 1.46 & $1.19,1.80$ & 1.47 & $1.21,1.79$ & 1.82 & $1.49,2.24$ \\
\hline Moisture and dampness & 1.0 & 1.40 & $1.08,1.81$ & 1.58 & $1.24,2.01$ & 1.68 & $1.30,2.16$ \\
\hline \multicolumn{8}{|l|}{ Social factors } \\
\hline Vandalism & 1.0 & 1.52 & $0.97,2.39$ & 1.39 & $0.92,2.10$ & 2.05 & $1.34,3.16$ \\
\hline Social difficulties & 1.0 & 1.14 & $0.85,1.53$ & 1.19 & $0.90,1.56$ & 1.40 & $1.06,1.90$ \\
\hline Noisy neighbors & 1.0 & 1.41 & $0.99,2.00$ & 1.49 & $1.07,2.08$ & 1.75 & $1.26,2.44$ \\
\hline \multicolumn{8}{|l|}{ Psychologic factors } \\
\hline Low perceived control & 1.0 & 1.17 & $0.79,1.74$ & 1.17 & $0.83,1.67$ & 1.26 & $0.87,1.83$ \\
\hline Passive coping & 1.0 & 1.31 & $0.90,1.90$ & 1.58 & $1.11,2.25$ & 1.46 & $1.01,2.12$ \\
\hline Depressive coping & 1.0 & 1.25 & $0.93,1.67$ & 1.32 & $1.01,1.74$ & 1.28 & $0.96,1.72$ \\
\hline \multicolumn{8}{|l|}{ Behavioral factors } \\
\hline Smoking & 1.0 & 1.11 & $0.95,1.29$ & 1.11 & $0.96,1.27$ & 1.30 & $1.11,1.52$ \\
\hline No physical activity & 1.0 & 1.49 & $1.05,2.12$ & 1.48 & $1.06,2.06$ & 1.48 & $1.04,2.10$ \\
\hline Excessive alcohol use & 1.0 & 0.98 & $0.73,1.32$ & 0.93 & $0.71,1.23$ & 1.17 & $0.89,1.54$ \\
\hline
\end{tabular}

we may have forgotten important confounders on the neighborhood level $(16,26)$. Neighborhoods do not only differ in their level of socioeconomic status. Neighborhood income inequality may be considered in this context, since area income inequality has been found to be related to mortality independent of mean area income level $(43,44)$. In further analyses of GLOBE data, we will use integral information from the municipal authorities on a wide range of neighborhood characteristics, possibly allowing us to examine potential neighborhood confounders.

Second, we examined whether social class during upbringing contributed to the neighborhood socioeconomic status-mortality association (4). Low background social class could be related to living in poorer areas, independent of adult social class, and low background social class has been found to be related to adult health $(45,46)$, also independent of adult social class. In our study, however, social class during upbringing did not affect the association between neighborhood socioeconomic status and mortality (not tabulated).

Third, our measures of baseline health status were selfreported only. Because of particular diseases, people may move to specific neighborhoods. To control for this confounding effect of disease, baseline health status should ideally have been measured through medical screenings. In our data, self-reported diseases were particularly underreported by the lower socioeconomic groups, causing underestimated socioeconomic differences in prevalent disease (47). In a longitudinal design in which prevalent disease is controlled for, this may, however, result in overestimated socioeconomic differences in mortality risks. This argument holds only when prevalent disease is considered a confounder. We think, however, that it is more likely that neighborhood socioeconomic status causes health to deteriorate, i.e., prevalent disease is an intermediate factor. In this perspective, our results may even be underestimated.

\section{Are neighborhood effects underestimated?}

Some methodological concerns that are likely to have caused underestimated effects of neighborhood socioeconomic status should also be discussed. First, the neighborhood boundaries were derived from the neighborhood classification scheme used by the municipal authorities. It is based upon areas that have relatively homogeneous types of houses (e.g., predominantly rented or private). It is possible that particular parts of neighborhoods are not correctly defined by this classification or that people perceive different boundaries to define their neighborhood. Neighborhoods, so defined, could be of similar, smaller, or larger magnitude. One of the strengths of the GLOBE study is the availability of many neighborhoods (relative to the population). Although this increases the socioeconomic homogeneity within neighborhoods, the incorrect classification of neighborhoods may still have resulted in misclassification, possibly leading to underestimated effects of neighborhood socioeconomic status $(5,16,26)$. Furthermore, the socioeconomic status of some neighborhoods was described by few respondents only, and students were excluded from the analyses. This may also have led to misclassification of the 
neighborhood socioeconomic status. It is not completely clear how this may have affected our findings. The results were, however, similar in subjects living in neighborhoods with many and those with few respondents.

Second, neighborhood socioeconomic status was stringently controlled for individual socioeconomic status, as if the latter were a confounder. In this perspective, people with a low socioeconomic status are thought to search for neighborhoods with a low socioeconomic status; because of their low income, they buy or rent cheaper houses in particular areas. From another perspective, a neighborhood with a low socioeconomic status is thought to result in less of a tendency among its inhabitants to study or to move up the social ladder (16). Here, the individual socioeconomic status should be considered as an intermediate factor. To the extent that the latter viewpoint is applicable, the adjustment for individual socioeconomic status has resulted in underestimated contextual effects, particularly because one neighborhood socioeconomic indicator was controlled for four individual socioeconomic indicators.

Third, because of a longer exposure to adverse socioeconomic neighborhood conditions, neighborhood socioeconomic effects may be stronger in persons who lived longer in particular neighborhoods $(16,18)$. We could not explore this effect specifically because there was no individual-level information on how long persons lived in their neighborhood. Municipal integral information on the neighborhood percent of persons living in the neighborhood for less than 3 years, however, did not interact with neighborhood socioeconomic status, i.e., neighborhood socioeconomic effects were not stronger when most people moved in a longer time ago (not tabulated).

Low neighborhood socioeconomic status was a consistent and substantial predictor of premature mortality in Dutch men and women. Since persons from lower and those from higher socioeconomic groups were equally adversely affected by living in such neighborhoods, neighborhood socioeconomic status had genuine contextual effects on mortality. Although more research is needed to determine the specific mechanisms involved, our findings pointed to a higher prevalence of poor housing conditions, social disintegration, adverse psychologic profiles, and unhealthy behaviors in neighborhoods with a low socioeconomic status. Both individual and neighborhood socioeconomic statuses were related to longevity. The independent effect of the latter suggests potential public health benefits of modifying socioeconomic characteristics of areas.

\section{ACKNOWLEDGMENTS}

Supported by grants from the Dutch Ministry of Public Health, Welfare, and Sports and the Dutch Prevention Fund.

The study is conducted in close collaboration with the Public Health Services of the Dutch city of Eindhoven and the region of South-East Brabant.

The authors thank Roel Faber, Ilse Oonk, and Michel Provoost for carefully constructing the database and Dr. Carola Schrijvers for providing comments on previous drafts of the paper.

\section{REFERENCES}

1. Anderson RT, Sorlie P, Backlund E, et al. Mortality effects of community socioeconomic status. Epidemiology 1997;8:42-7.

2. Blaxter M. Health and lifestyles. London, England: Tavistock/ Routledge, 1990.

3. Carstairs V, Morris R. Deprivation and mortality: an alternative to social class? Community Med 1989;11:210-19.

4. Davey Smith G, Hart C, Watt G, et al. Individual social class, area-based deprivation, cardiovascular disease risk factors, and mortality: the Renfrew and Paisley study. J Epidemiol Community Health 1998;52:399-405.

5. Diez-Roux AV, Nieto J, Muntaner C, et al. Neighborhood environments and coronary heart disease: a multilevel analysis. Am J Epidemiol 1997;146:48-63.

6. Diez-Roux AV, Nieto FJ, Caulfield L, et al. Neighbourhood differences in diet: the Atherosclerosis Risk in Communities (ARIC) Study. J Epidemiol Community Health 1999;53:55-63.

7. Eachus J, Williams M, Chan P, et al. Deprivation and cause specific morbidity: evidence from the Somerset and Avon survey of health. BMJ 1996;312:287-92.

8. Ecob R, Jones K Mortality variations in England and Wales between types of place: an analysis of the ONS longitudinal study. Office of National Statistics. Soc Sci Med 1998;47: 2055-66.

9. Ellaway A, Macintyre S. Does where you live predict health related behaviours?: A case study in Glasgow. Health Bull (Edinb) 1996;54:443-6.

10. Freeman H. Schizophrenia and city residence. Br J Psychiatry 1994;164 (Suppl. 23):39-50.

11. Haan M, Kaplan GA, Camacho T. Poverty and health: prospective evidence from the Alameda County Study. Am J Epidemiol 1987;125:989-98.

12. Hart C, Ecob R, Davey Smith G. People, places and coronary heart disease risk factors: a multilevel analysis of the Scottish Heart Health Study Archive. Soc Sci Med 1997;45:893-902.

13. Kammerling RM, O'Connor S. Unemployment rate as predictor of rate of psychiatric admission. BMJ 1993;307:1536-9.

14. Kleinschmidt I, Hills M, Elliott P. Smoking behavior can be predicted by neighborhood deprivation measures. J Epidemiol Community Health 1995;49 (Suppl. 2):S72-7.

15. McLoone P, Boddy FA. Deprivation and mortality in Scotland, 1981 and 1991. BMJ 1994;309:1465-70.

16. Robert SA. Community-level socioeconomic status effects on adult health. J Health Soc Behav 1998;39:18-37.

17. Sloggett A, Joshi H. Deprivation indicators as predictors of life events 1981-1992 based on the UK ONS Longitudinal Study. J Epidemiol Community Health 1998;52:228-33.

18. Waitzman NJ, Smith KR. Phantom of the area: poverty-area and mortality in the United States. Am J Public Health 1998;88: 973-6.

19. Woodward M. Small area statistics as markers for personal social status in the Scottish Heart Health Study. J Epidemiol Community Health 1996;50:570-6.

20. Yen IH, Kaplan GA. Neighborhood social environment and risk of death: multilevel evidence from the Alameda County Study. Am J Epidemiol 1999;149:898-907.

21. Yen IH, Kaplan GA. Poverty area residence and changes in depression and perceived health status: evidence from the Alameda County Study. Int J Epidemiol 1999;28:90-4.

22. Duncan C, Jones K, Moon G. Psychiatric morbidity: a multilevel approach to regional variations in the UK. J Epidemiol Community Health 1995;49:290-5.

23. Reijneveld SA. The impact of individual and area characteristics on urban socioeconomic differences in health and smoking. Int J Epidemiol 1998;27:33-40.

24. Reijneveld SA, Schene AH. Higher prevalence of mental disorders in socioeconomically deprived areas in the Netherlands: community or personal disadvantage? J Epidemiol Community Health 1998;52:2-7.

25. Sloggett A, Joshi H. Higher mortality in deprived areas: community or personal disadvantage. BMJ 1994;309:1470-4.

26. Diez-Roux AV. Bringing context back into epidemiology: vari- 
ables and fallacies in multilevel analysis. Am J Public Health 1998;88:216-22.

27. Kaplan GA. People and places: contrasting perspectives on the association between social class and health. Int J Health Serv 1996;26:507-19.

28. Macintyre S, MacIver S, Sooman A. Area, class and health: should we be focusing on places or people? J Social Policy 1993;22:213-34.

29. Marmot MG. Improvement of social environment to improve health. Lancet 1997;351:57-60.

30. Schwartz S. The fallacy of the ecological fallacy: the potential misuse of a concept and the consequences. Am J Public Health 1994;84:819-24.

31. Susser M. The logic in ecological. I. The logic of analysis. Am J Public Health 1994;84:825-9.

32. Yen IH, Syme SL. The social environment and health: a discussion of the epidemiologic literature. Annu Rev Public Health 1999;20:287-308.

33. Mackenbach JP, van de Mheen H, Stronks K. A prospective cohort study investigating the explanation of socioeconomic inequalities in health in the Netherlands. Soc Sci Med 1994;38: 299-308.

34. Schrijvers CT, Stronks K, van de Mheen H, et al. Explaining educational differences in mortality: the role of behavioral and material factors. Am J Public Health 1999;89:535-40.

35. Erikson R, Goldthorpe J, Portocarero L. Intergenerational class mobility and the convergence thesis: England, France and Sweden. Br J Sociol 1983;34:303-42.

36. Stronks K, van de Mheen H, Looman CW, et al. Cultural, material, and psychosocial correlates of the socioeconomic gradient in smoking behavior among adults. Prev Med 1997;
26:754-66.

37. Stronks K, van de Mheen H, Looman CW, et al. The importance of psychosocial stressors for socioeconomic inequalities in perceived health. Soc Sci Med 1998;46:611-23.

38. Goldstein H. Multilevel statistical models. London, England: Edward Arnold, 1995.

39. Woodhouse G. Multilevel modelling applications. A guide for users of MLn. Multilevel Models Project, Institute of Education. London, England: University of London, 1996.

40. Putnam RD, Leonardi R, Nanetti RY. Making democracy work. Princeton, NJ: Princeton University Press, 1993.

41. Kawachi I, Kennedy BP. Health and social cohesion: why care about income inequality? BMJ 1997;314:1037-40.

42. Bartley M. Unemployment and ill health: understanding the relationship. J Epidemiol Community Health 1994;48:333-7.

43. Ben-Shlomo Y, White IR, Marmot M. Does the variation in the socio-economic characteristics of an area affect mortality? BMJ 1996;312:1013-14.

44. Wilkinson RG. Unhealthy societies. The afflictions of inequality. London, England: Routledge, 1996.

45. Bosma H, van de Mheen H, Mackenbach JP. Social class in childhood and general health in adulthood: a questionnaire study of contribution of psychological attributes. BMJ 1999; 318:18-22.

46. van de Mheen H, Stronks K, Looman CWN, et al. Does childhood socio-economic status influence health through behavioural factors? Int J Epidemiol 1998;27:431-7.

47. Mackenbach JP, Looman CW, van der Meer JB. Differences in the misreporting of chronic conditions, by level of education: the effect on inequalities in prevalence rates. Am J Public Health 1996;86:706-11. 